\title{
PROFIL SOSIAL EKONOMI DAN STATUS GIZI PETANI DI LOMBOK TENGAH NUSA TENGGARA BARAT
}

\author{
(Socio Economic and Nutritional Status Profile of Farmers \\ in Central Lombok, Nusa Tenggara Barat)
}

\author{
Dadang Sukandar ${ }^{1}$ \\ ${ }^{1}$ Staf Pengajar Departemen Gizi Masyarakat, Fakultas Ekologi Manusia (FEMA) IPB \\ Telp: 0251-8628304/8621258; Fax: 0251-8625846/8622276
}

\begin{abstract}
Socio-conomic and nutritional status are nutrition problems in Indonesia. Solution to overcome this problem is therefore needed. Objectives of this study are 1) to asses socioeconomic, 2) to asess nutritional status of community and 3) to improve nutritional status through conducting training on food, nutrition, sanitation and hygiene. Study was conducted in Central Lombok, Nusa Tenggara Barat, from December 1995 to November 2006. A sample of size 63 households was drawn randomly from household population of size 316. The households population is household farmer who are beneficiary of Special Program for Food Secutity, Food and Acgriculture Organization. Data were analyzed quantitatively and qualitatively and presented in table. Reseacrh results show that level of income of farmer is still very low. Average income of farmer is only Rp 99.141 per capita per month. Most portion of expenditure or as much as $72 \%$ is spent for food. There are still many husbands-wives who have nutrition problem. As much as $30 \%$ of husbands are thin and $4 \%$ are overweight. As much as $11 \%$ wives are thin and $11 \%$ are overweight. After attending trainning, the knowledge on nutrition and food of the farmers increase significantly, therefore it is hoped that their knowledge can improve their nutritional status.
\end{abstract}

Keywords: socio-economic, food, nutrition, sanitation, hygiene.

\section{PENDAHULUAN}

\section{Latar Belakang}

Krisis ekonomi yang menimpa Indonesia sekitar 10 tahun lalu memberikan dampak terhadap berbagai aspek kehidupan. Krisis tersebut telah menurunkan pendapatan masyarakat. Disamping itu jumlah orang miskin juga meningkat. Data menunjukkan bahwa $25 \%$ juta orang Indonesia adalah orang miskin. Ini berarti bahwa jumlah orang miskin di indonesia sebanyak 40 juta orang.

Walaupun tidak semua orang Indonesia tidak termasuk miskin menurut kriteria Badan Pusat Statistik, tapi banyak di antara mereka yang mengalami periode krisis pangan. Data SUSENAS tahun 1990 menunjukkan bahwa 40\% rumah tangga mengalami periode krisis pangan.

Kemiskinan erat kaitannya dengan kemampuan rumah tangga untuk memenuhi kebutuhan dasar, yang antara lain adalah pangan.

Kemiskinan telah menyebabkan penurunan daya beli masyarakat. Kemampuan orang untuk membeli stok pangan sangat rendah, sementara harga terus meningkat. Rendahnya daya beli orang telah menurunkan tingkat konsumsi gizi keluarga. Oleh karenanya tingkat kesejahteraan keluarga menurun.

Daya beli yang rendah adalah suatu indikator krisis pangan. J umlah rumah tangga yang mengalami krisis pangan meningkat setelah krisis ekonomi. Kuantitas dan kualitas pangan yang dikonsumsi tidak cukup. Kondisi ini telah menyebabkan berbagai kasus kurang gizi. Harper, Driskel dan Deaton (1985) menyatakan bahwa kemiskinan dan kurang gizi adalah faktor penting dalam masalah kurang gizi. Penyebab lain adalah kurangnya pengetahuan gizi atau ketidak mampuan menerapkan pengetahuan ke dalam praktek dalam kehidupan sehari-hari mereka.

\section{Tujuan}

Penelitian ini bertujuan untuk mendapatkan gambaran keadaan sosial ekonomi masyarakat, menganalisis status gizi petani serta memperbaiki pengetahuan pangan, gizi, sanitasi dan higiene keluarga petani yang ada di 
wilayah Lombok Tengah, Nusa Tenggara Barat melalui kegiatan pelatihan.

\section{METODE PENELITIAN}

\section{Desain, Tempat dan Waktu Penelitian}

Penelitian ini menggunakan desain crosssectional dengan cara survai. Penelitian dilakukan di Lombok Tengah, Provinsi Nusa Tenggara Barat. Penelitian dilakukan sejak bulan Desember 2005 sampai November 2006.

\section{Prosedur Penarikan Contoh}

Populasi didefinisikan sebagai kumpulan keluarga petani yang tergabung ke dalam kelompok tani yang mendapat bantuan dari Special Program for Food Security, Food and Agriculture Organization. Populasi tersebut berukuran 1401 untuk seluruh petani SPFS (Special Program for Food Security) di Indonesia dan 482 keluarga di Kota Banjar. Dari populasi tersebut ditarik contoh melalui teknik penarikan contoh acak berlapis, dalam hal ini kelompok tani berdiri sebagi lapis. Penentuan ukuran contoh dilakukan sebagai berikut:

Penentuan ukuran sampel didasarkan kepada penarikan contoh acak sederhana dengan formula (Cochran, 1982) sebagai berikut:

$$
n=\frac{n_{o}}{1+\frac{n_{o}-1}{N}}
$$

keterangan:

$$
\begin{aligned}
n_{o}= & \frac{p(1-p) t_{\alpha / 2}^{2}(v)}{d^{2}} \\
\mathrm{n}= & \text { ukuran sampel rumahtangga } \\
\mathrm{P}= & \text { penduga proporsi keluarga yang in- } \\
& \text { take energi dan proteinnya di ba- } \\
& \text { wah } 70 \% \text { (rendah) } \\
= & \text { keakurasian mutlak perbedaan an- } \\
& \text { tara parameter } \mathrm{p} \text { dan } \mathrm{p} \\
\mathrm{d} \quad & \text { suatu nilai sehingga } \mathrm{P}\left(-\mathrm{t}_{\alpha / 2}(\mathrm{v}) \nless<\right. \\
& \left.\mathrm{t}_{\alpha / 2}(\mathrm{v})\right)=1-\alpha, \mathrm{t} \text { adalah peubah acak } \\
& \text { fungsi kepekatan } \mathrm{t}-\mathrm{student} \text { dengan } \\
\mathrm{t}_{\alpha / 2}(\mathrm{v}) & \text { derajat bebas } \mathrm{v} \\
= & \text { ukuran populasi }
\end{aligned}
$$

Dasar untuk menentukan ukuran contoh adalah penduga proporsi keluarga yang konsumsi energi dan proteinnya rendah. Agar contoh serupa dengan populasinya, $\alpha$ dan $d$ yang dipilih harus rendah. Untuk menentukan n, $\alpha=0.05$ dan $d=0.053958$ dipilih karena cukup baik.
Khomsan et al. (2005) menunjukkan bahwa proporsi keluarga yang konsumsi energi dan proteinnya di bawah $70 \%$ adalah $p>0.4$ oleh karena itu $p=0.5$ dipilih untuk menduga ragam $p(1-p)$. Substitusi $\alpha=0.05, d=0.053958, p=0.4$ dan $\mathrm{N}=482$ ke dalam formula menghasilkan ukuran contoh $n=92$.

Penarikan contoh acak berlapis dengan alokasi proporsional digunakan untuk menentukan ukuran contoh dari tiap kelompok tani. Ukuran contoh dari kelompok tani ditentukan sebagai berikut:

$$
n_{i}=\frac{N_{i}}{N} n
$$

keterangan:

$\mathrm{n}_{\mathrm{i}} \quad=$ ukuran contoh kelompok tani ke-i

$\mathrm{N}_{\mathrm{i}}=$ ukuran kelompok tani ke-i

$\mathrm{N}=$ ukuran populasi

$\mathrm{n}=$ ukuran contoh

Dengan menggunakan formula di atas, ukuran contoh untuk semua kelompok tani didaftarkan di Tabel 1.

Tabel 1. Daftar Ukuran Contoh Kelompok Tani $\left(n_{i}\right)$

\begin{tabular}{lcc}
\hline \multicolumn{1}{c}{ Kelompok Tani } & $\mathbf{N}_{\mathbf{i}}$ & $\mathbf{n}_{\mathbf{i}}$ \\
\hline 1. Maju Bersama & 50 & 10 \\
2. Patuh Angen & 55 & 11 \\
3. Patuh Karya & 70 & 14 \\
4. Gelepak Mandiri & 53 & 10 \\
5. Amanah & 38 & 8 \\
6. Sukur Gati & 50 & 10 \\
\hline J umlah & $\mathbf{3 1 6}$ & $\mathbf{6 3}$ \\
\hline
\end{tabular}

\section{Jenis dan Cara Pengumpulan Data}

Data yang dikumpulkan mencakup namanama anggota keluarga, jenis kelamin; umur, fisiologi, pendidikan, berat badan, tinggi badan, konsumsi pangan, pendapatan, pengeluaran dan pengetahuan gizi. Dalam tulisan ini tidak semua data tersebut disajikan

\section{Pelatihan}

Pelatihan dilakukan dalam dua tahap. Tahap pertama dilakukan terhadap para pelatih yang berasal dari Dinas Kesehatan Lombok Tengah. Pelatihan tahap pertama dilakukan pada bulan Maret 2006 selama 7 hari. Materi yang dilatihkan mencakup pengetahun gizi dasar, keamanan pangan, cara memilih dan mengolah makanan, perencanaan tingkat rumahtangga, sanitasi dan higiene serta penyaringan air. Tahap kedua adalah pelatihan terhadap para petani yang dilakukan oleh para pelatih yang telah dilatih. Pelatihan tahap ke- 
dua dilakukan dari Juni sampai Agustus 2006. Dalam Pelatihan diawali dengan pretest Ialu diakhiri posttest untuk tiap materi.

\section{Pengolahan dan Analisis Data}

Pengolahan data mencakup editing, penyusunan struktur file, data entry, editing data pada file komputer dan sorting. Pengolahan data dilakukan dengan menggunakan program Mirosoft Excel for Windows.

Komputasi dilakukan untuk menduga mean, simpangan baku, nilai minimum dan maksimum untuk pengetahuan gizi awal dan akhir, hasilnya disajikan dalam tabel. Analisis data dilakukan dengan menggunakan progam Statistical Analysis System (SAS) (1985).

\section{HASIL DAN PEMBAHASAN}

\section{Jumlah Anggota Keluarga}

Rata-rata jumlah anggota keluarga tergolong sedang yaitu sebesar 4.7 orang per keluarga seperti dapat dilihat pada Tabel 2 . Keragaman jumlah anggota keluarga tergolong sedang, yaitu ditunjukkan dengan simpangan baku sebesar 2 orang. Jumlah anggota keluarga minimum 2 oarang dan maksiumum 11 orang.

Tabel 2. Statistik jumlah anggota Keluarga

\begin{tabular}{cc}
\hline Statistik & $\begin{array}{c}\text { J umlah Anggota } \\
\text { keluarga }\end{array}$ \\
\hline mean & 4.7 \\
std & 2.0 \\
min & 2.0 \\
max & 11.0 \\
\hline
\end{tabular}

\section{Pendidikan dan Umur Suami-Istri}

Rata-rata umur suami istri tergolong pertengahan. Rata-rata umur istri adalah 37 tahun, sedangkan suami adalah 44 tahun. Umur istri berkisar antara 19 sampai 60 tahun, sedangkan umur suami berkisar antara 23 sampai 75 tahun seperti dapat dilihat pada Tabel 3.

Rata-rata pendidikan suami istri tergolong sangat rendah. Rata-rata pendidikan istri adalah 1.8 tahun atau setara kelas 2 SD, sedangkan suami adalah 2.7 tahun atau juga setara kelas 3 SD. Pendidikan suami berkisar antara 0 sampai 12, sedangkan istri berkisar dari 0 sampai 11 tahun seperti dapat dilihat pada Tabel 3.
Tabel 3. Statistik Umur dan Pendidikan SuamiIstri

\begin{tabular}{ccccc}
\hline \multirow{2}{*}{ Statistik } & \multicolumn{2}{c}{ Istri } & \multicolumn{2}{c}{ Suami } \\
\cline { 2 - 5 } & Umur & Pend & Umur & Pend \\
\hline mean & 37 & 1.8 & 44 & 2.7 \\
std & 11 & 2.8 & 13 & 3.3 \\
min & 19 & 0 & 23 & 0 \\
max & 60 & 11 & 75 & 12 \\
\hline
\end{tabular}

Catatan: Pend $=$ Pendidikan

\section{Pendapatan dan Pengeluaran}

Pendapatan keluarga petani tergolong masih sangat rendah. Tabel 4 menunjukkan bahwa rata-rata pendapatan hanya sebesar Rp 99 141/ kapita/ bulan jauh dibawah garis kemiskinan Badan Pusat Statistik (BPS) sebesar Rp 150 000/ kapita/ bulan. Sebagian besar pendapatan digunakan untuk pengeluaran pangan. Hal ini ditunjukkan oleh rata-rata persentase pengeluaran pangan sebesar $72 \%$ dengan standar deviasinya sebesar $12 \%$

Rata-rata pengeluaran pangan dan non pangan sebesar Rp 93069 per kapita per bulan hampir mendekati pendapatan. Karena sebesar $72 \%$ dibelanjakkan untuk pangan maka hanya $28 \%$ dibelanjakkan untuk non pangan atau hanya sekitar Rp 26 000/ kapita/bulan. Hal ini menunjukkan bahwa tingkat kesejahteraan mereka masih sangat rendah.

Tabel 4. Statistik Pendapatan dan Pengeluaran Keluarga Petani.

\begin{tabular}{lccc}
\hline \multirow{2}{*}{ Stat. } & \multicolumn{2}{c}{ Rp/kapita/bulan } & \begin{tabular}{c} 
\% Penge- \\
luaran \\
\cline { 2 - 3 } pangan
\end{tabular} \\
\cline { 2 - 3 } Pendapatan & Pengeluaran & 72 \\
mean & 99141 & 93069 & 12 \\
std & 44434 & 39698 & 25 \\
min & 21417 & 21417 & 90 \\
max & 212500 & 208266 & \\
\hline
\end{tabular}

\section{Status Gizi}

Rata-rata status gizi menurut Indeks Massa Tubuh (IMT) suami-istri petani tergolong normal. Rata-rata IMT suami sebesar 20.6 dan rata-rata IMT istri sebesar 21.1 seperti dapat ditunjukkan oleh Tabel 4. Namun demikian tidak berarti tidak ada masalah gizi suami istri. Tabel 5 menunjukkan bahwa masih ada masalah gizi kurang dan gizi lebih pada suami istri tersebut. Suami yang berstatus gizi kurang sebanyak 30\% dan bergizi lebih sebanyak $4 \%$ Sementara istri yang berstatus gizi kurang sebanyak $11 \%$ demikian pula istri yang berstatus gizi lebih sebanyak $11 \%$ 
Tabel 5. Statistik Status Gizi Suami-Istri

\begin{tabular}{lrrrrrr}
\hline \multirow{2}{*}{ Stat. } & \multicolumn{3}{c}{ Suami } & \multicolumn{3}{c}{ Istri } \\
\cline { 2 - 7 } & BB & TB & IMT & BB & \multicolumn{1}{c}{ TB } & \multicolumn{1}{c}{ IMT } \\
\hline mean & 53.8 & 162 & 20.6 & 47.5 & 150.4 & 21.1 \\
std & 8.8 & 9.8 & 3.7 & 6.0 & 7.2 & 2.7 \\
min & 39 & 143 & 15.6 & 36 & 127 & 16.9 \\
max & 75 & 183 & 41.5 & 61 & 165 & 27.3 \\
\hline
\end{tabular}

Keterangan: $\mathrm{BB}=$ Berat Badan $(\mathrm{kg})$,

TB $=$ Tinggi Badan $(\mathrm{cm})$ IMT $=\mathrm{BB} /(\mathrm{TB} / 100)^{2}$

Tabel 6. Sebaran Keluarga menurut Kategori IMT

\begin{tabular}{lcccc}
\hline \multirow{2}{*}{ IMT } & \multicolumn{2}{c}{ Suami } & \multicolumn{2}{c}{ Istri } \\
\cline { 2 - 5 } & $\mathbf{n}$ & $\%$ & $\mathbf{n}$ & $\%$ \\
\hline Kurang $(<18.5)$ & 18 & 30 & 7 & 11 \\
Normal $(18.5-25)$ & 40 & 66 & 49 & 78 \\
Lebih $(>25)$ & 3 & 4 & 7 & 11 \\
\hline
\end{tabular}

\section{Hasil Pelatihan}

Materi pengetahuan gizi dan higiene yang dilatihkan mencakup pengetahuan gizi dasar, keamanan pangan, pemilihan dan pengolahan pangan, perencanaan pangan tingkat rumahtangga, sanitasi dan higiene serta penyaringan air.

Tabel 7. Hasil Pre dan Posttest Pelatihan Gizi, Sanitasi dan Higiene

\begin{tabular}{|c|c|c|c|}
\hline Stat. & Pre-test & Post-test & Delta \\
\hline \multicolumn{4}{|c|}{ Pengetahuan Gizi Dasar } \\
\hline mean & 4.6 & 6.4 & 1.8 \\
\hline std & 1.1 & 1 & 1.1 \\
\hline $\min$ & 2 & 4 & -1 \\
\hline $\max$ & 7 & 9 & 5 \\
\hline \multicolumn{4}{|c|}{ Keamanan Pangan } \\
\hline mean & 4.6 & 6.5 & 1.9 \\
\hline std & 1.1 & 1 & 1 \\
\hline $\min$ & 2 & 4 & -1 \\
\hline $\max$ & 7 & 10 & 4 \\
\hline \multicolumn{4}{|c|}{ Pemilihan \& Pengolahan Pangan } \\
\hline mean & 4.8 & 6.7 & 1.9 \\
\hline std & 1 & 1.1 & 1 \\
\hline $\min$ & 2 & 4 & -1 \\
\hline $\max$ & 7 & 10 & 4 \\
\hline \multicolumn{4}{|c|}{ Perencanaan Pangan Tingkat } \\
\hline mean & 4.8 & 6.5 & 1.8 \\
\hline std & 1.1 & 1.2 & 1.1 \\
\hline $\min$ & 2 & 4 & -2 \\
\hline $\max$ & 7 & 10 & 4 \\
\hline \multicolumn{4}{|c|}{ Sanitasi dan Higiene } \\
\hline mean & 5 & 6.9 & 1.9 \\
\hline std & 1 & 1.1 & 1 \\
\hline $\min$ & 3 & 5 & -1 \\
\hline $\max$ & 7 & 10 & 5 \\
\hline \multicolumn{4}{|c|}{ Penyaringan Air } \\
\hline mean & 5.2 & 7.1 & 1.9 \\
\hline std & 1 & 1.2 & 1 \\
\hline $\min$ & 3 & 4 & -1 \\
\hline $\max$ & 8 & 10 & 4 \\
\hline
\end{tabular}

Pretest dan posttest dilakukan dengan menggunakan skala 0-10. Hasil pretest menunjukkan bahwa rata-rata skor ke enam materi yang dilatihkan masih rendah yaitu berkisar antara 4.6 sampai 5.2. Setelah Pelatihan, hasil posttest menunjukkan adanya peningkatan dengan rata-rata berkisar antara 6.4 sampai 6.7. Rata-rata peningkatan tersebut berkisar antara 1.8 sampai 1.9 .

\section{KESIMPULAN}

Pendidikan suami-istri petani masih sangat rendah. Hal ini ditunjukkan dengan ratarata pendidikan suami hanya kelas 2 SD dan rata-rata pendidikan istri hanya kelas $3 \mathrm{SD}$. Kesejahteraan keluarga petani masih sangat rendah. Hal ini ditunjukkan oleh rata-rata pendapatan yang hanya Rp 99 141/ kapita/ bulan. Sebanyak $72 \%$ pengeluaran digunakan untuk pangan.

Masih cukup banyak suami-istri yang berstatus gizi kurang dan lebih. Sebanyak 30\%suami berstatus gizi kurang dan $4 \%$ berstatus gizi lebih. Sebanyak $11 \%$ istri berstatus gizi lebih dan $11 \%$ lagi dari istri berstatus gizi lebih.

Pelatihan telah dapat meningkatkan pengetahuan gizi, sanitasi dan higiene mereka dengan kenaikan sekitar 1.9 poin dalam skala 0-10 dari sebelumnya dengan rata-rata di bawah 5.2 menjadi rata-rata di atas 6.4.

\section{DAFTAR PUSTAKA}

Cochran WG. 1982. Sampling Technique. J ohn Wiley \& Sons.

Harper LJ, Deaton, \& Driskel JA. Food, Nutrition and Agriculture. UI Press, J akarta.

Khomsan A, Dadang S, Faisal A, Hadi R. \& Eddi SM. 2005. Research on Food and Nutritional Status of Poor Households In Highland and Coastal Areas. Bogor Agricultural University.

SAS Institute Inc. 1985. Procedure Guide for Personal Computer, Version 6 Edition. Cary, North Carolina. 